\title{
Renal Hypoplasia: Case Literature Review
}

\section{Manisha Nakhate ${ }^{1}$, Varsha Bande ${ }^{* 2}$, Manisha Mishra ${ }^{4}$, Rajesh Kumar ${ }^{5}$.}

${ }^{1}$ Professor and Head, Department of Anatomy, D.Y. Patil Medical College, Navi Mumbai, Maharashtra, India.

*2 Associate Professor, Department of Anatomy, D.Y. Patil Medical College, Navi Mumbai, Maharashtra, India.

${ }^{3}$ Assistant Lecturer, Department of Anatomy, D.Y. Patil Medical College, Navi Mumbai, Maharashtra, India.

${ }^{4}$ Department of Anatomy, AllMS New Delhi, India.

\section{ABSTRACT}

Introduction: Congenital anomalies of kidney and urinary tract (CAKUT) presents a broad range of disorders including abnormal renal parenchymal development, disrupted parenchymal development, abnormalities of lower urinary tract, urinary collecting system. The knowledge of these anomalies will help the clinicians and surgeons during the procedures of kidney. The purpose of this article is to present one of the cases of renal hypoplasia and the review that highlights renal hypoplasia cases.

Methodology: A vertical incision has been made in midline from xiphoid process to pubic symphysis encircling the umbilicus, another incision from pubic symphysis laterally up to the anterior superior iliac tubercle along the iliac crest to expose the abdominal cavity. Details of the position suprarenal gland and the upper poles of the kidneys and external appearance of kidneys in situ were noted. The arrangement of the attached structures such as the hilum with structures passing through, ureter, bladder, abdominal aorta and the inferior vena cava were also noted and recorded.

Observation and Result: The size of the left kidney was found small in comparison to right kidney. Coronal section of left kidney also showed a smaller number of renal pyramids, major calyces and minor calyces.

Conclusion: The knowledge of anatomical variations of urinary system has a significant role for clinicians and surgeons for diagnosing diseases including congenital anomalies, radiological interpretations, procedures, surgical interventions and management of clinical conditions.

KEY WORDS: Renal Hypoplasia, Congenital Anomalies Of Kidney And Ureter, Cadavers, Dissection.

Corresponding Author: Dr Varsha Pravin Bande, 1102, bldg. no 10, Clover, Everest World CHS, Dhokali Naka, Kolshet road, Thane west 400607, Maharashtra, India.

E-Mail: drvarshanavgire@gmail.com

Access this Article online

Quick Response code

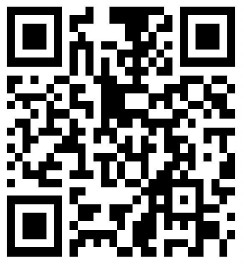

DOI: $10.16965 /$ ijar.2021.203

Journal Information

\section{International Journal of Anatomy and Research}

ISSN (E) 2321-4287 | ISSN (P) 2321-8967

https://www.ijmhr.org/ijar.htm

DOI-Prefix: https://dx.doi.org/10.16965/ijar

\section{(c) $\overline{E r-M o-s i}$}

\section{Article Information}

Received: 13 Dec 2021

Peer Review: 14 Dec 2021

Revised: 06 Jan 2022
Accepted: 25 Jan 2022

Published (O): 05 Mar 2022

Published (P): 05 Mar 2022

\section{INTRODUCTION}

Different congenital anomalies of the kidney and urinary tract cause significant morbidity and mortality in subjects. Renal hypoplasia, dysplasia and agenesis are heterogeneous disorders included in the group of Congenital Anomalies of the Kidney and Urinary Tract
(CAKUT) [1]. The incidence of these congenital anomalies is found to be 1 in 3640-4300 live births; most of them are sporadic, familial cases [2]. These anomalies may be associated with multicystic dysplastic kidney, reflux nephropathies, ureteral or urethral atresia, 
uretero-pelvic junction obstruction, ureterovesicular junction obstruction, mega-ureter, posterior urethral valves and anterior urethral diverticulum [3-5].

The Merriman-Webster dictionary defines hypoplasia as "A condition of arrested development in which an organ or its part, remains below the normal size or in immature state". Renal hypoplasia is defined as abnormally small kidneys with normal morphology and reduced number of nephrons. According to this definition; hypoplasia is present in $2.2 \%$ of the population, whereas many epidemiologic studies suggest that an estimated incidence of renal hypoplasia is 400 births [6]. Commonly renal hypoplasia is of three types; simple hypoplasia, oligo-meganephronic hypoplasia and segmental hypoplasia. These 3 types of hypoplasia showed gross and microscopic differences among them but all have a common feature of reduction in number of renal lobes [7-10]. A fourth type may be present, but commonly not recognized that is the cortical hypoplasia where nephrogenesis is normal but consists of a reduced number of nephron generations which results in cortical thinning and medullary reduction $[8,9]$.

In addition to above mentioned types of renal hypoplasia, there is also, a concept of reduced nephron number, or reduced nephron endowment, known as oligonephronia which may lead the predisposition to adult onset hypertension and chronic kidney disease (CKD) [11,12].

The diminutive or small sized kidney is one weighing less than 100 grams. There are mainly two factors which may cause a small sized kidney. The first is hypoplasia, which refers to abnormally small kidneys (greater than two standard deviations below the expected mean when correlated with age or other growth parameters), in which the kidney is miniature or rudimentary at birth due to arrested development. These kidneys are presented with normal morphology but with reduced number of nephrons [11]. The second is pyelonephritic atrophy, resulting from infection or obstruction in which atrophy is due to nephron-fibrosis usually takes place in a kidney of normal size at birth [13]. Renal hypoplasia is associated with infection, formation of stone, scarring with fibrosis, cystic degeneration and round cell infiltration. It is commonly associated with other congenital anomalies of the genitourinary tract.

The etiology and pathogenic factors involved in the development of renal hypoplasia have been well mentioned in many literatures. In many articles it is mentioned that this condition can be produced because of the failure of development of metanephrogenic blastema or metanephrogenic duct or primary vascular deficiency. The kidney develops from the Wolffian body through the stages of pronephros, mesonephros and metanephros. An insufficient blood supply occurring at any of those stages could cause arrest in development of kidney [12].

Development of the mammalian metanephric kidney is dependent on reciprocal inductive interactions between two distinct cell lineages, the ureteric cell lineage and the metanephric mesenchyme cell lineage [11].

The excretory unit of kidney developed from the metanephric mesenchyme cell lineage i.e. metanephric mesoderm and collecting ducts of kidney developed from the ureteric cell lineage i.e. ureteric bud. Renal hypoplasia can also occur due to inadequate ureteral bud branching and results in a small kidney with histologically normal nephrons, though few in number [13].

Genetic studies performed in humans and mutant mice have suggested that nephron endowment and kidney size is regulated by different factors such as number of critical genes, in utero environmental factors and molecular mechanisms [13]. Nephron formation is dependent on inductive signals from the ureteric tip; therefore, the number of ureteric tips is considered as a strong determinant of nephron endowment. However, division of ureteric bud tip is dependent on inductive signals emerging from the metanephric mesenchyme. The GDNF/RET signalling axis is principally regulate ureteric branching. GDNF (glial-derived neurotrophic factor), the ligand for ureteric bud tip- specific RET (receptor tyrosine kinase), receptor (and GFR1), is 
exclusively expressed in the metanephric mesenchyme and is crucial for ureteric branching morphogenesis. Although mice with absence of GDNF, shows absence of kidneys and ureters due to deficient ureteric bud induction [14-16], GDNF heterozygous mice possesses reduced ureteric branching and significantly reduced size of kidney and a $30 \%$ reduction in number of nephrons [17]. Genetic studies in humans and mice have brought a valuable information regarding genetic contribution and molecular mechanisms leading to normal nephron endowment and renal hypoplasia. Specifically, the roles of several critical parallel and interacting signalling pathways such as GDNF/Ret, FGF (fibroblast growth factor), PAX2 (paired box 2), and $\mathrm{HH}$ (Hedgehog) which have been primarily involved in the pathogenesis of renal hypoplasia.

\section{METHODOLOGY}

The present case was reported during routine cadaveric dissection of a 75 years old female cadaver in an academic setting of a medical college, Navi Mumbai, Maharashtra. As per the Cunningham's manual of practical anatomy volume-2 (Thorax and Abdomen), anterior abdominal wall and abdominal cavity was opened [18].

For this, a vertical incision has been made in midline from xiphoid process to pubic symphysis encircling the umbilicus, another incision has been made from pubic symphysis laterally up to the anterior superior iliac tubercle along the iliac crest to expose the abdominal cavity. Then the skin, superficial fascia, muscles of anterior abdominal wall with aponeurosis were reflected. Then the peritoneal cavity was explored and folds of the peritoneum were reflected. All anterior abdominal viscera were examined in situ and were removed for exposure of posterior abdominal wall. Pararenal fat in both paravertebral gutter between the level of T12 to L3 vertebrae was removed to expose the anterior layer of renal fascia. A vertical incision has been taken through renal fascia and perirenal fat was removed which surrounds the kidney and suprarenal glands. The position of thesuprarenal gland and the upper poles of the kidneys were noted and recorded. Details of the position and external appearance of kidneys in situ were noted. The arrangement of the attached structures such as the hilum with structures passing through, ureter, bladder, abdominal aorta and the inferior vena cava were also noted and recorded.

\section{OBSERVATIONS AND RESULTS}

Observation was made on a dissected specimen for the presence of any variations in the morphology of kidney and ureter. Both kidneys were situated on the posterior abdominal wall, behind the peritoneum on either side of vertebral column.

Right Kidney: External features (Fig 1): The size and shape of the right kidney was normal. It is placed between T12-L3 vertebrae. The hilum is anteriorly placed with arrangement of structures from anterior to posterior as renal artery, renal vein and renal pelvis. A single renal artery was noted arising from abdominal aorta. A single renal vein was noted draining into inferior vena cava. The length and width of the ureter was normal and opened into the bladder at right lateral trigone of the bladder through a narrow orifice.

Coronal section (Fig 2): Coronal section of right kidney showed outer dark renal cortex and inner pale renal medulla. The medulla was incorporated by 7 renal pyramids, 3 major calyces and 6 minor calyces.

Left Kidney: External features (Fig 1): The size of the left kidney was small in comparison to a normal kidney and was placed at the vertebral level of T12-L2. The hilum is anteriorly placed with arrangement of structures from anterior to posterior as renal artery, renal vein and renal pelvis. A single renal artery was noted arising from abdominal aorta. A single renal vein was noted draining into inferior vena cava. The length and width of the ureter was normal and opened into the bladder at left lateral trigone of the bladder through a narrow orifice.

Coronal section (Fig 2): Coronal section of left kidney had outer dark renal cortex and inner pale renal medulla. The medulla showed 5 renal pyramids, 2 major calyces and 4 minor calyces. 


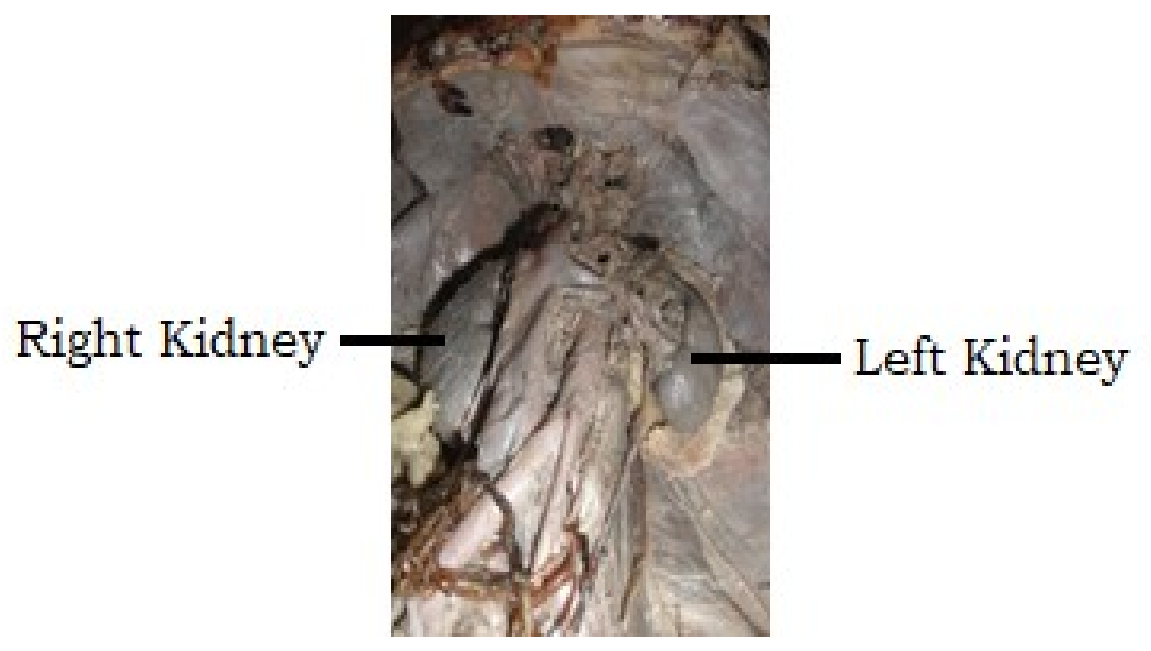

Fig. 1: Right normal kidney and left hypoplastic kidney.

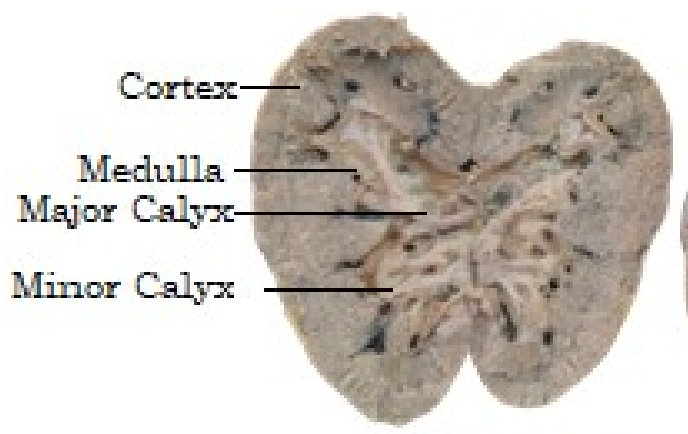

Right Kidney

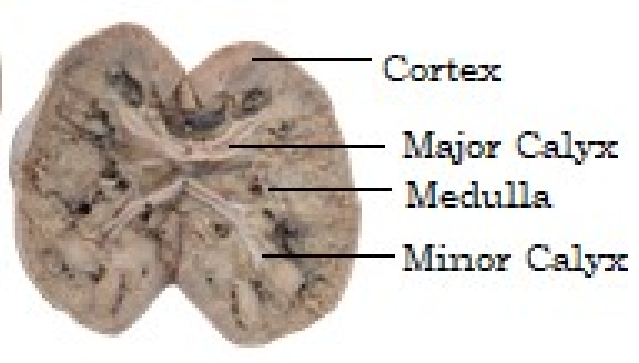

Left Kidney

Fig. 2: Coronal sections of kidneys.

\section{DISCUSSION}

Congenital anomalies of the kidneys and urinary tract are most common types of congenital malformations. Cadaveric study is important and relevant even in this modern era of imaging techniques. The review on hypoplastic kidneys will be provided by this manuscript.

During routine academic dissection sessions; Shweta B Shambharkar et al (2020) examined bilateral kidneys and ureters in 50 human adult cadavers ( 31 male and 19 female) over a period of 3 years in the department of Anatomy, Grant govt. medical college, Mumbai. Hypoplastic kidneys were found in 05.05\% cadavers. Total kidneys observed were 99 in 50 cadavers as one cadaver had unilateral renal agenesis. Total 27 cases had anatomical variations belonging to both kidneys and ureters means $27.27 \%$ out of 99 kidneys. They reported $05.05 \%$ hypoplastic kidneys. They found 5 in total ( 4 in male and 1 in female) hypoplastic kidneys. The one male cadaver out of four had bilateral atrophic kidneys. Atrophic kidneys were found 2 on right side and 3 on left side. In one case, the left hypoplastic kidney was very small of $16 \mathrm{gms}$, with compensatory hypertrophy of opposite kidney. In another case, right kidney was atrophied weighing $35 \mathrm{gms}$, with hypertrophic opposite kidney. In other case, both kidneys were atrophied with fetal lobulations. In one case case, right kidney showed a thin slender mass of parenchyma and left kidney showed uneven hypertrophy at upper pole [19].

Stephan M. Bonsib studied 18 cases of renal hypoplasia, out of which 9 cases are of segmental hypoplasia with or without cortical hypoplasia, 8 cases of simple hypoplasia with or without cortical hypoplasia and 1 case of cortical hypoplasia with normal number of renal lobes and no cases from oligomeganephronia were included in the study. The cases satisfy the criteria for hypoplasia as defined by Rubinstein and colleagues. All cases were diagnosed on nephrectomy specimens. In this study they had studied the Radial Glomerular Count which employed sections oriented along medullary rays for estimation of number of nephron generations. The glomerular layers on each side of medullary rays were recorded [20]. 
Kathleen $\mathrm{R}$ Lockhart et al described a case of 21-year-old woman who presented with low volume continuous incontinence and uterus didelphys. On CT intravenous pyelogram right kidney was not identified but excretory phase images suggested the presence of right ureter. On Diethylenetriaminepentaacetic acid renogram confirmed an area of perfusion consistent with a poorly functioning right kidney remnant. A laparoscopic right nephrectomy was performed, with a new application of indocyanine green aiding which showed right hypoplastic kidney with fluorescence imaging [21].

Sarojini Raman et al reported 2 cases of hypoplastic kidneys out of which one is 20-year-old pregnant female who came for routine antenatal check-up with complain of mild pain in left flank. on USG Abdomen and pelvis showed small sized left kidney with mild hydronephrosis and dilated ureter. Right kidney showed compensatory hypertrophy. $X$-ray IVU revealed non-excretion of contrast from left kidney [Table/Fig-2]. CECT KUB/CT IVU showed small sized left kidney with no excretion of contrast from left kidney.

Another one is a two-year-old female child who came to paediatric surgery OPD with haematuria on Ultrasonography of abdomen and pelvis showed the right kidney measuring $2.3 \mathrm{~cm}$ in length with a thin cortex and dilated right ureter. The left kidney had features of compensatory hypertrophy [22].

Payal A Kasat et al studied 90 dissected human cadavers to see the shape, position and number of kidneys and ureters over a period of 5 years. They found hypoplastic kidneys in 3.3\% cadavers. Hypoplastic kidneys were seen in 3 cadavers among 90 dissected cadavers. Out of which one cadaver had unilateral left hypoplastic kidney with lobulated surface and its coronal section showed cystic degeneration; while bilateral hypoplastic kidneys were seen in 2 cadavers [23]. Pabbati R Reddy studied 50 human cadavers; who were died due to renal failure and posted for post mortem. Out of those 50 cadavers, 5 of them showed congenital renal anomaly counting $10 \%$ of the deaths because of renal failure in adults and one case with congenital hypoplasia. A narrow ureter also found in the patient who had congenital hypoplasia of the left kidney. The size and shape of the right kidney was normal measuring $12 \times 5 \times 2 \mathrm{~cm}$ and placed at the level of T12-L3, while the left kidney was smaller compared to right kidney measuring $7 \times 4 \times 2 \mathrm{~cm}$ and placed between T11-L1 [24].

Ayu Ogawa et al found a hospitalised case of 21 years old woman for proteinuria and mild renal dysfunction. Her serum creatinine level was $1.10 \mathrm{mg} / \mathrm{dl}$ and estimated glomerular filtration rate $53.9 \mathrm{ml} / \mathrm{min}$ per $1.73 \mathrm{~m} 2$. On abdominal CT right kidney showed renal hypoplasia. She had also complained of mixed hearing disturbance and a history of surgeries for correction of left cervical branchial fistulae and bilateral preauricular pits. She was suspected to have branchio-oto-renal (BOR) syndrome which has prevalence of approximately 1 in 40,000 and it is associated with several genetic mutations in EYA1, SIX1, SALL1, and SIX5 [25].

\section{CONCLUSION}

Kidney and urinary tract malformations are most frequently detected anomalies. The knowledge of anatomical variations of urinary system has a significant role for clinicians and surgeons for diagnosing diseases including congenital anomalies, radiological interpretations, procedures, surgical interventions and management of clinical conditions.

\section{SOURCE OF FUNDING: Nil}

\section{Conflicts of Interests}

Authors have no conflict of interest. The authors alone are responsible for the content and writing of the paper.

\section{DECLARATION}

The authors have no financial or proprietary interest in any material discussed in this article.

\section{AUTHORS CONTRIBUTIONS}

All authors have contributed equally to the manuscript. All authors read and approved the final manuscript.

\section{ACKNOWLEDGEMENTS}

The authors sincerely thank those who donated their bodies to science so that 
anatomical research could be performed. Results from such research can potentially increase mankind's overall knowledge that can improve patient care. Therefore, these donors and their families deserve our highest gratitude.

\section{REFERENCES}

[1]. Winyard P, Feather S. Genetics of human kidney malformations. Nephrology Dialysis Transplantation. 1996 Jun 1;11(6):976-8.

[2]. Rukmangadha N, Chowhan AK, Patnayak R, Radhika K, Phaneendra BV, Lakshmi AY, Reddy MK. Multicystic dysplastic kidney: a retrospective study with clinicopathological correlation. J Clin Sci Res. 2013;2:88-93.

[3]. Debnath J, Singh H, Kapur K, Bhattacharya TK. Multicystic dysplastic kidneys: antenatal diagnosis. Medical Journal, Armed Forces India. 2004 Jul;60(3):310.

[4]. Aytaç B, Sehitođlu I, Vuruskan H. Multicystic dysplastic kidney: four-year evaluation. Turk Patoloji Derg. 2011 Sep 1;27(3):210-4.

[5]. Ylinen E, Ahonen S, Ala-Houhala M, Wikström S. Nephrectomy for multicystic dysplastic kidney: if and when?. Urology. 2004 Apr 1;63(4):768-71.

[6]. Hiraoka M, Tsukahara H, Ohshima Y, Kasuga K, Ishihara Y, Mayumi M. Renal aplasia is the predominant cause of congenital solitary kidneys. Kidney international. 2002 May 1;61(5):1840-4.

[7]. Rubenstein M, Meyer R, Bernstein J. Congenital abnormalities of the urinary system: I. A postmortem survey of developmental anomalies and acquired congenital lesions in a children's hospital. The Journal of pediatrics. 1961 Mar 1;58(3):35666.

[8]. Bernstein J, Meyer R. Some speculations on the nature and significance of developmentally small kidneys (renal hypoplasia). Nephron. 1964; 1(3):137-43.

[9]. Bernstein J. Developmental abnormalities of th renal parenchyma-renal hypoplasia and dysplasia. Pathol. Ann.. 1986;3:213-47.

[10]. Holcomb Jr G. Renal dysgenesis and cystic disease of the kidney: A report of the committee on terminology, nomenclature and classification, section on urology, american academy of pediatrics: K. Glassberg, F. Stephens, R. Lebowitz, et al. J Urol 138: 1085-1092,(October), 1987. Journal of Pediatric Surgery. 1988 Jul 1;23(7):686.

[11]. Cain JE, Di Giovanni V, Smeeton J, Rosenblum ND. Genetics of renal hypoplasia: insights into the mechanisms controlling nephron endowment. Pediatric research. 2010 Aug;68(2):91-8.
[12]. Mathé CP. THE DIMINUTIVE KIDNEY-Congenital Hypoplasia and Atrophic Pyelonephritis. California medicine. 1956 Feb;84(2):110.

[13]. Moore MW, Klein RD, Fariñas I, Sauer H, Armanini M, Phillips H, Reichardt LF, Ryan AM, Carver-Moore K, Rosenthal A. Renal and neuronal abnormalities in mice lacking GDNF. Nature. 1996 Jul;382(6586):76-9.

[14]. Moore MW, Klein RD, Fariñas I, Sauer H, Armanini M, Phillips $H$, Reichardt LF, Ryan AM, Carver-Moore K, Rosenthal A. Renal and neuronal abnormalities in mice lacking GDNF. Nature. 1996 Jul;382(6586):76-9.

[15]. Pichel JG, Shen L, Sheng HZ, Granholm AC, Drago J, Grinberg A, Lee EJ, Huang SP, Saarma M, Hoffer BJ, Sariola $H$. Defects in enteric innervation and kidney development in mice lacking GDNF. Nature. 1996 Jul;382(6586):73-6.

[16]. Sánchez MP, Silos-Santiago I, Frisén J, He B, Lira SA, Barbacid M. Renal agenesis and the absence of enteric neurons in mice lacking GDNF. Nature. 1996 Jul;382(6586):70-3.

[17]. Cullen-McEwen LA, Drago J, Bertram JF. Nephron endowment in glial cell line-derived neurotrophic factor (GDNF) heterozygous mice. Kidney international. 2001 Jul 1;60(1):31-6.

[18]. Romanes GJ. Cunningham's manual of practical anatomy.

[19]. Shambharkar SB, Borate S, Ratta AK, Gangane S. MORPHOLOGICAL STUDY OF KIDNEY IN CADAVERS OF WESTERN MAHARASHTRA REGION. Int J Anat Res. 2020;8(3.2):7680-91.

[20]. Bonsib SM. Renal hypoplasia, from grossly insufficient to not quite enough: consideration for expanded concepts based upon the author's perspective with historical review. Advances in Anatomic Pathology. 2020 Sep;27(5):311.

[21]. Lockhart KR, Saul M, Blatt A. Novel approach to locating a hypoplastic kidney in a unique variant of uterine didelphys syndrome presenting with continuous incontinence. BMJ Case Reports CP. 2019 Dec 1;12(12):e229570.

[22]. RAMAN S, PADHY SK, RATH J, SENAPATI U. Hypoplastic dysplasia of kidney with hydroureter: two cases. Journal of Clinical and Diagnostic Research. 2019 Jun 1;13(6):12-5.

[23]. Kasat P, Bhosale Y, Muthiyan G. A cadaveric study of variations in the urological system. Int J Anat Res. 2018;6(3.3):5686-94.

[24]. Reddy, P.R., 2017. A study of congenital renal anomalies in adult cadavers. Indian Journal of Clinical Anatomy and Physiology, 4(2), pp.181-4.

[25]. Ogawa A, Kitamura S, Nakayama K, Sugiyama H, Morisada N, lijima K, Makino H. Right hypoplastic kidney. Kidney international. 2012 Nov 1;82(9):1037. Literature Review. Int J Anat Res 2022;10(1):8269-8274. DOI: 10.16965/ijar.2021.203 